\title{
Caracterização Mecânica de Polipropileno Reciclado para a Indústria Automotiva
}

\author{
Beatriz L. Fernandes, Antonio J. Domingues \\ Engenharia Mecânica, PUC-PR
}

\begin{abstract}
Resumo: A indústria automotiva responde, atualmente, por uma grande parte do mercado de consumo de plásticos, por isso existe um crescente interesse no investimento em processos de reciclagem, inclusive devido à vinculação às atividades relacionadas à proteção ambiental. Dentre as peças automotivas, os pára-choques são relativamente fáceis de serem reciclados devido às suas dimensões e por constituírem, geralmente, de um único material, o polipropileno (PP). Neste trabalho, analisaram-se as propriedades mecânicas de misturas de PP virgem e reciclado, em três porcentagens diferentes, a fim de detectar as alterações das mesmas, relacionando-as à qualidade do produto. Concluiu-se que porcentagens de reciclado acima de $30 \%$ causam deterioração das propriedades mecânicas do produto. Este estudo visa a fornecer uma contribuição para o aumento na utilização de plásticos reciclados na indústria automotiva.
\end{abstract}

Palavras-chave: Reciclagem de polipropileno, caracterização mecânica, pára-choques automotivos.

\section{Mechanical Characterization of Recycled Polypropylene for Automotive Industry}

Abstract: The automotive industry is now responsible for a large share of plastic consumption, which prompted increasing investments in recycling processes, also due to the need of ambient protection. Among the automotives parts, bumpers are relatively easy to be recycled due to their dimensions and because they are made of a single material, polypropylene (PP). In this work, the mechanical properties of mixtures of virgin and recycled PP, in three different percentages, were analyzed in order to detect alterations and associate them with the product quality. It was concluded that percentages of recycled material above $30 \%$ deteriorate the mechanical properties of the product. This study aims to provide a contribution to the increase in the recycled plastic use in the automotive industry.

Keywords: Polypropylene recycling, mechanical characterization, automotive bumpers.

\section{Introdução}

O aumento do custo das resinas plásticas, pressionado pelas constantes flutuações do preço do petróleo no mercado internacional, tem estimulado as pesquisas em reciclagem de polímeros. Normalmente, o preço do plástico reciclado é $40 \%$ mais baixo do que o da resina virgem. Portanto, a substituição da resina virgem pela reciclada traz benefícios de redução de custo e aumento da competitividade, além de auxiliar na preservação ambiental.

Embora uma grande quantidade de metais, polímeros, borrachas e outros tipos de materiais sejam utilizados na indústria automotiva, sob o ponto de vista da reciclagem, pode-se verificar que os polímeros são os materiais que apresentam propriedades mecânicas inferiores, quando reciclados $^{[1]}$.

A reciclagem é essencial para a reutilização dos recursos aplicados durante a vida útil de um automóvel e existe um crescente interesse da indústria automotiva nas atividades relacionadas à proteção ambiental.
Dentre as peças automotivas, os pára-choques são relativamente fáceis de serem reciclados devido às suas dimensões e por constituírem, geralmente, de um único material, o polipropileno (PP). A maioria dos pára-choques, no entanto, é pintado para melhorar a sua aparência e a sua resistência ao ataque químico do ambiente. Pedaços de tinta se misturam aos produtos reciclados prejudicando as propriedades físicas, mecânicas e a qualidade superficial das peças ${ }^{[2]}$.

É prática comum, na indústria de fabricação de párachoque, a utilização de uma porcentagem de até $10 \%$ de material reciclado, misturado ao virgem. Este limite de reciclado é permitido pelos compradores que alegam não interferir nas propriedades mecânicas exigidas em normas específicas adotadas pelas empresas.

O objetivo deste trabalho foi analisar as propriedades mecânicas de misturas de PP virgem e reciclado. Foram utilizados corpos de prova padrão, injetados com duas misturas de PP, 30\% reciclado e 70\% virgem, $50 \%$ reciclado e $50 \%$ virgem e $100 \%$ reciclado, comparando-as com o material $100 \%$ virgem. 


\section{Materiais e Métodos}

O material utilizado foi o PP granulado, especialmente fornecido para a fabricação de pára-choques. Os materiais e misturas são mostrados na Tabela 1 , referenciados nos resultados, discussões e conclusões deste trabalho.

Os parâmetros para a injeção dos corpos de prova foram os mesmos utilizados para a conformação dos pára-choques. No entanto, uma segunda injeção foi realizada com a amostra com $100 \%$ de reciclado, com um aumento nas temperaturas nas regiões do cilindro de injeção que correspondem à região de plastificação do material. $\mathrm{O}$ aumento de temperatura foi de $20{ }^{\circ} \mathrm{C}$ (de 180 para $200{ }^{\circ} \mathrm{C}$ ). Isso foi necessário, pois notouse falhas no preenchimento das peças nas temperaturas mais baixas.

O ensaio de tração foi realizado seguindo o procedimento da norma ASTM D638, onde os parâmetros de ensaio são definidos como:

- Taxa de aplicação de carga: $5 \mathrm{~mm} / \mathrm{min}$;

- Temperatura de ensaio: $23 \pm 2{ }^{\circ} \mathrm{C}$;

- Umidade relativa: $50 \pm 5 \%$.

As dimensões dos corpos de prova injetados são mostradas na Figura 1.

Durante o ensaio, verificou-se que com uma taxa de $5 \mathrm{~mm} / \mathrm{min}$, o corpo de prova continuava a se deformar sem chegar à ruptura após 5 minutos. Segundo a norma, o ensaio

Tabela 1. Materiais utilizados nos ensaios.

\begin{tabular}{ccc}
\hline & \multicolumn{2}{c}{ PP (\%) } \\
\cline { 2 - 3 } Designação & Virgem & Reciclado \\
\hline $100 \%$ virgem & 100 & - \\
$30 \%$ reciclado & 70 & 30 \\
$50 \%$ reciclado & 50 & 50 \\
$100 \%$ reciclado & - & 100 \\
\hline
\end{tabular}

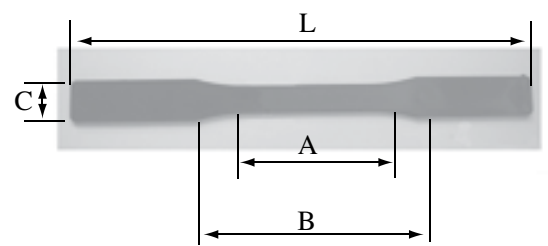

Figura 1. Corpo de prova para o ensaio de tração. $\mathrm{L}=215 \mathrm{~mm}, \mathrm{~A}=60 \mathrm{~mm}$, $\mathrm{B}=100 \mathrm{~mm}, \mathrm{C}=19 \mathrm{~mm}$ e espessura $=3 \mathrm{~mm}$.

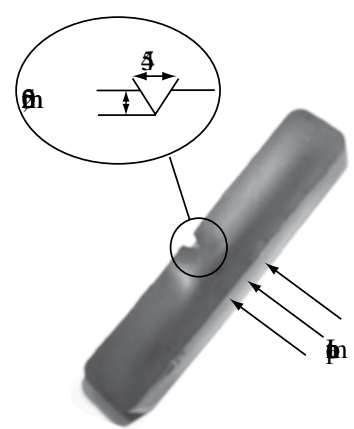

Figura 2. Corpo de prova para o ensaio Charpy, segundo a norma ASTM D6110. não deve ultrapassar este tempo, por isso, a taxa ideal para os materiais utilizados neste trabalho foi de $45 \mathrm{~mm} / \mathrm{min}$. Esta taxa foi mantida para todas as misturas, incluindo o PP virgem e o PP $100 \%$ reciclado. O ensaio foi realizado em uma máquina de tração EMIC DL 500 ${ }^{[3]}$.

O objetivo do ensaio de impacto é medir a resistência de um corpo de prova padrão a uma solicitação dinâmica através de uma máquina de ensaio pendular. Para este ensaio utilizouse a norma ASTM D6110, onde os corpos de prova injetados possuíam as dimensões e entalhes ilustrados na Figura 2. O ensaio foi realizado em um pêndulo de $3 \mathrm{~J}$, na temperatura de aproximadamente $20^{\circ} \mathrm{C}$.

\section{Resultados e Discussão}

A Tabela 2 mostra os valores médios das propriedades mecânicas extraídas dos ensaios de tração realizados em cinco amostras de PP virgem, $30 \%$ reciclado, $50 \%$ reciclado e $100 \%$ reciclado com temperatura de injeção de $200{ }^{\circ} \mathrm{C}$. Na Tabela, $\sigma_{\mathrm{t}}$ e $\varepsilon_{\mathrm{t}}$ representam a tensão e a deformação de tração, respectivamente e $\sigma_{\mathrm{r}}$ e $\varepsilon_{\mathrm{r}}$ representam a tensão e a deformação na ruptura, respectivamente.

Através da Tabela 2, pode-se notar uma diminuição da deformação na ruptura do corpo de prova, com o aumento da porcentagem de reciclado. Essa menor deformação acarreta em um aumento do módulo elástico do material, ou seja, este se torna mais rígido. Para a utilização em pára-choques, é necessário que o material sofra uma deformação sob impacto, a fim de absorver energia suficiente para impedir a transferência dessa energia para o condutor. Portanto, dentre as porcentagens utilizadas, apenas o material com $30 \%$ de reciclado se aproxima do valor de deformação adequado, ou seja, valor próximo ao do $100 \%$ virgem. Acima de $30 \%$ pode-se perceber uma brusca diminuição desse valor, impossibilitando a sua utilização para esta aplicação.

Durante o ensaio de tração, todos os materiais apresentaram comportamentos muito similares até que a tensão de tração foi atingida. A partir desse ponto os comportamentos foram bem distintos e dependentes da porcentagem de reciclado.

Notou-se que, com o aumento da quantidade de reciclado houve um também um aumento da quantidade de defeitos nas peças. Esses defeitos não interferiram no comportamento mecânico de forma significativa até que a força máxima fosse atingida. A partir deste ponto, onde a propagação de trincas tem uma grande influência na deformação até a ruptura, os defeitos foram determinantes na deformação.

Para a maioria dos fabricantes de pára-choques e laterais de automóveis, a tensão de tração do material deve estar em cerca de $20 \mathrm{MPa}$. Através dos dados extraídos, nota-se que a resistência à tração de todos os materiais se encontra próximo ao valor exigido. No entanto, houve um pequeno aumento à medida que a quantidade de reciclado também aumentou e isso é reflexo do aumento na fragilidade do material, confirmada no 
Tabela 2. Média das Propriedades mecânicas das amostras retiradas do ensaio de tração.

\begin{tabular}{ccccc}
\hline Corpo de prova & $\sigma \mathbf{t}(\mathbf{M P a})$ & $\sigma \mathbf{r}(\mathbf{M P a})$ & $\varepsilon \mathbf{t}(\boldsymbol{\%})$ & $\varepsilon \mathbf{r}(\boldsymbol{\%})$ \\
\hline 100\% virgem & $18,9 \pm 0,1$ & $16,5 \pm 0,1$ & $7,1 \pm 1,0$ & $400,9 \pm 28,8$ \\
30\% reciclado & $20,5 \pm 0,1$ & $18,6 \pm 0,1$ & $7,5 \pm 1,5$ & $343,9 \pm 33,4$ \\
50\% reciclado & $21,2 \pm 0,1$ & $15,1 \pm 0,1$ & $6,7 \pm 1,0$ & $80,9 \pm 5,8$ \\
$100 \%$ reciclado & $22,6 \pm 0,1$ & $16,6 \pm 0,2$ & $5,1 \pm 1,1$ & $11,3 \pm 3,9$ \\
\hline
\end{tabular}

Tabela 3. Valores das resistências ao impacto em kJ/m².

\begin{tabular}{cc}
\hline Amostra & Resistência ao impacto $\left(\mathbf{k J} / \mathbf{m}^{2}\right)$ \\
\hline $100 \%$ virgem & 78,7 \\
$30 \%$ reciclado & 55,1 \\
$50 \%$ reciclado & 42,3 \\
$100 \%$ reciclado & 19,7 \\
\hline
\end{tabular}

ensaio de impacto. Esse aumento da fragilidade pode inviabilizar a utilização do material na fabricação de pára-choques.

A Tabela 3 mostra os valores extraídos do ensaio de impacto Charpy realizado nas amostras de PP virgem, $100 \%$ reciclado e nas misturas.

Existe a exigência, pelos fabricantes de automóveis, de uma resistência ao impacto mínima de $35 \mathrm{~kJ} / \mathrm{m}^{2}$. Considerando que a área da seção transversal dos corpos de prova ensaiados foi de $101,6 \mathrm{~mm}^{2}\left(101,6 \times 10^{-6} \mathrm{~m}^{2}\right)$ tem-se, na Tabela 3 , os valores médios das resistências ao impacto em $\mathrm{kJ} / \mathrm{m}^{2}$ para cada material ensaiado. Foram utilizados 10 corpos de prova por material.

Os materiais com 30 e $50 \%$ de reciclado apresentaram valores de resistência ao impacto superiores ao exigido. No entanto, somente esta propriedade não define a qualidade do material para a aplicação na indústria automotiva.

Através dos dados pode-se observar uma queda brusca no valor da energia absorvida por $\mathrm{m}^{2}$, para o material $100 \%$ reciclado. A superfície de fratura desses corpos de prova, mostrou vários poros dentro do material que foram responsáveis pela fragilização do mesmo.

$\mathrm{O}$ aumento de defeitos com o aumento da porcentagem de reciclado é justificado pelo maior valor de viscosidade do material plastificado, em relação ao $100 \%$ virgem, confirmado durante o processo de injeção das peças. Para o $100 \%$ reciclado, em particular, a alta viscosidade dificultou o preenchimento do molde sendo necessário aumentar a temperatura de injeção, o que acarreta um aumento do custo de fabricação da peça.

Houve diminuição significativa na resistência ao impacto das misturas em relação ao material virgem, embora essas amostras não tenham apresentado defeitos. Os dados mostram a influência do reciclado no aumento da rigidez do material.

\section{Conclusões}

Os resultados obtidos permitem concluir que o material reciclado fragiliza o $\mathrm{PP}$, diminuindo a sua deformação na ruptura, embora o material com $30 \%$ de reciclado tenha apresentado um comportamento próximo ao do virgem. Quanto à tensão de tração, o material com $30 \%$ de reciclado atendeu às exigências dos fabricantes de pára-choques.

O ensaio de impacto confirmou a fragilização do PP, principalmente com misturas acima de $30 \%$ de reciclado, embora o valor de resistência ao impacto com misturas de até $50 \%$ de reciclado tenha atingido as exigências dos fabricantes de pára-choques.

Uma mistura de $30 \%$ de reciclado no PP virgem apresenta as propriedades mecânicas estudadas satisfatórias para aplicação em pára-choques. Esta mistura também apresenta bom desempenho durante o processo de injeção, cujos parâmetros foram mantidos em relação à injeção do material virgem e nenhum defeito foi identificado nas peças injetadas com esta mistura.

Como os resultados apresentados mostram a deterioração brusca das propriedades mecânicas a partir da mistura com $50 \%$ de reciclado, seria interessante a repetição dos estudos apresentados neste trabalho para faixas mais estreitas para misturas entre 30 e $50 \%$ de reciclado.

\section{Agradecimentos}

Os autores agradecem o apoio Prof. Dr. Ricardo Diego Torres e ao aluno Renato Gomes de Araújo pelo auxílio nos ensaios mecânicos.

\section{Referências Bibliográficas}

1. Otha, H.; Tohno, H. \& Uruji, T. - New Technologies, 14, p. 51 (2002).

2. Ohori, N.; Suyama, T.; Yamamoto N. \& Yagi, N. - Technical Notes/JSAE Reviews, 17, p.401 (1996).

3. Canevarolo Jr., S. V. - "Técnicas de Caracterização de Polímeros”, Artliber, São Paulo (2004).

Recebido: $19 / 07 / 06$ Aceito: 07/12/06 